J. Lake Sci. (湖泊科学), 2018, 30(1): 130-138

DOI 10. 18307/2018. 0113

(c) 2018 by Journal of Lake Sciences

\title{
冷季不同植物人工湿地处理生活污水的工程实例分析
}

\author{
周卿伟 ${ }^{1,2}$, 梁银秀 ${ }^{1,2}$, 阎百兴 ${ }^{1}$, 刘兴土 ${ }^{1,2}$, 于翔霏 ${ }^{1,2}$, 穆炜峑 $^{3}$, 张泽清 $^{4}$, 祝 惠 $^{1 * *}$ \\ (1:中国科学院东北地理与农业生态研究所湿地生态与环境研究中心, 长春 130102) \\ (2: 中国科学院大学,北京 100049) \\ (3: 福建省永春县环境监测站, 泉州 362600) \\ (4:福建省永春县环境监察大队,泉州 362600$)$
}

\begin{abstract}
摘 要: 本实验以亚热带地区福建省永春县农村生活污水作为处理对象, 选取 10 种湿地植物, 构建具有不同植物类型的 表面流人工湿地的实例工程, 比较不同植物配置人工湿地的处理能力, 以及湿地植物的生物量和植物体内氮、磷累积能 力. 研究结果表明, 水龙和美人蕉人工湿地具有较高的铵态氮去除能力, 去除率可分别达到 $76.7 \%$ 和 $87.7 \%$; 两者同时也 对总氮表现出较好的去除效果, 尤其是美人蕉人工湿地在冬季节对总氮的去除率可维持在 $80.3 \%$ 以上; 2014 年初冬季节 实验结果表明, 水龙还具有一定的总磷去除能力, 去除率可达到 $69.0 \%$. 水龙和美人蕉具有较大的生物量, 其单位面积干 重可分别达到 0.46 和 $0.30 \mathrm{~kg} / \mathrm{m}^{2}$, 又能较好地积累氮、磷元素, 其体内氮含量可分别达到 6.43 和 $4.60 \mathrm{~g} / \mathrm{m}^{2}$, 磷含量可分 别达到 0.50 和 $1.01 \mathrm{~g} / \mathrm{m}^{2}$. 综上所述, 种植水龙和美人蕉的人工湿地总体处理效果较好, 同时又能更多地积累氮、磷元素, 且具有更大的生物量, 可选为相对适宜用于处理生活污水的适合亚热带地区应用的人工湿地植物.
\end{abstract}

关键词: 湿地植物;水龙;美人蕉;面源污染;生活污水;亚热带; 冬季

\section{The constructed wetlands engineering cases with different plants treating domestic sewage in a subtropical climate at cold seasons}

ZHOU Qingwei ${ }^{1,2}$, LIANG Yinxiu $^{1,2}$, YAN Baixing ${ }^{1}$, LIU Xingtu ${ }^{1,2}$, YU Xiangfei ${ }^{1,2}$, MU Weiyin ${ }^{3}$, ZHANG Zeqing $^{4} \&$ ZHU Hui ${ }^{1 * *}$

(1: Key Laboratory of Wetland Ecology and Environment, Northeast Institute of Geography and Agroecology, Chinese Acade-

my of Sciences, Changchun 130102, P.R.China)

(2: University of Chinese Academy of Sciences, Beijing 100049, P.R.China)

(3: Yongchun Environmental Monitoring Station, Fujian Province, Quanzhou 362600, P.R.China)

(4: Yongchun Environmental Supervision Brigade, Fujian Province, Quanzhou 362600, P.R.China)

Abstract: Ten pilot-scale surface flow constructed wetland systems (SFCWs) engineering cases with respective different vegetation species were constructed to treat the rural domestic sewage in subtropical area at cold season (Yongchun City, Fujian Province). The efficiency of SFCWs, the biomass of vegetation, and contents of nitrogen (N) and phosphorous ( P) in aboveground biomass were investigated in this current study. In the reduction of ammonia nitrogen $\left(\mathrm{NH}_{4}^{+}-\mathrm{N}\right)$, the $\mathrm{SFCWs}$ of Jussiaea repens and Canna indica showed excellent performance, and the $\mathrm{NH}_{4}^{+}-\mathrm{N}$ removal percentages in $\mathrm{SFCWs}$ with both above species were $76.7 \%$ and $87.7 \%$, respectively. Additionally, SFCWs with $C$. indica also showed good performance in the reduction of total nitrogen ( TN). Over $80.3 \%$ of TN was removed in SFCW engineering case, which planted with $C$. indica in early and deep winter. The experiment also revealed that those two vegetation species could remove total phosphorus ( TP). The TP removal percentage by $J$. repens reached $69.0 \%$ in the experiment conducted in the fall of 2014, and SFCWs with $C$. indica could also remove TP, although it showed a lower removal percentage than J. repens. J. repens and C. indica could also have high biomass and high nutrients ( N, P)

* 国家重点基础研究发展计划“973”项目 (2013CB430401) 和泉州市院士专家工作站项目联合资助. 2016-12-09 收稿; 2017-04-21 收修改稿. 周卿伟( 1988 ), 男,博士研究生; E-mail: zhou520qingwei@ 126.com.

** 通信作者; E-mail: zhuhui@ iga.ac.cn. 
contents in their aboveground tissues comparing to the other vegetation species. The dry biomass of $J$. repens and $C$. indica were 0.46 and $0.30 \mathrm{~kg} / \mathrm{m}^{2}$, respectively. The tissue nitrogen contents of $J$. repens and $C$. indica were 6.43 and $4.60 \mathrm{~g} / \mathrm{m}^{2}$, respectively. The tissue phosphorus contents of $J$. repens and $C$. indica were 0.50 and $1.01 \mathrm{~g} / \mathrm{m}^{2}$, respectively. The result of this study indicated that $J$. repens and $C$. indica could be selected as potential SFCWs engineering case vegetation species for the treatment of rural domestic sewage in subtropical regions, due to their good performance, high biomass and strong nutrients uptake ability.

Keywords: Wetland vegetation; Jussiaea repens; Canna indica; non-point source pollution; domestic sewage; subtropical; winter

近年来随着我国农村经济的迅猛发展,农村生活污水排放量也越来越大 ${ }^{[1]}$. 同时, 我国农村人口数量巨 大, 居住分散, 又缺少基本的污水收集和处理设施, 大量生活污水未经处理直接排放, 导致大面积地表水体 富营养化污染 ${ }^{[2-4]}$. 人工湿地作为一种新型生态污水处理装置, 由于操作管理简单、运行维护方便等特点十 分适宜于我国农村生活污水的治理 ${ }^{[5-7]}$. 表面流人工湿地, 作为一种典型的人工湿地系统, 由于空气直接接 触水体, 存在大气复氧能力, 可极大地提高湿地对有机物和铵态氮的去除效果 ${ }^{[8]}$. 同时表面流人工湿地的植 被类型也较为丰富,包括沉水、浮水、挺水等多种水生植被类型 ${ }^{[9]}$. 因此, 表面流人工湿地十分适合用于人工 湿地植物的篮选.

湿地植物作为人工湿地最明显的生物特征, 是人工湿地的重要组成部分 ${ }^{[10]}$. 大量研究表明不同种类的 湿地植物去污能力差异明显, 例如, 有研究表明, 菱白、芦苇、水烛、灯心草和美人蕉对铵态氮的去除效果较 好 ${ }^{[11]}$; 风车草和香根草在处理高浓度的养殖废水时, 对有机物的去除率可达到 $90 \%$ 以上 ${ }^{[12]}$. 此外, 湿地植物 还能通过根系的泌氧能力、生化反应酶的释放以及改变水力传输特征等方面间接促进污染物的去除 ${ }^{[13-15]}$. 因此, 在人工湿地的构建过程中, 湿地植物的篮选显得尤为重要.

亚热带地区虽然水生植物资源比较丰富, 但目前关于适宜于亚热带气候条件下人工湿地的植物种类篮 选研究还较少 ${ }^{[16]}$. 此外, 虽然亚热带地区秋、冬季温度高于北方, 但在秋、冬季 (冷季), 由于温度降低, 湿地 植物的生长受到影响或者易出现枯死现象, 影响湿地净化效果和景观效果 ${ }^{[17-19]}$. 因此, 篮选该气候条件下, 尤其是秋、冬季(冷季) 低温条件下, 依旧具有较好去除能力的湿地植物就显得非常重要, 有利于人工湿地在 亚热带地区的推广和应用.

本次人工湿地植物篎选实验在具有典型亚热带气候区的福建省泉州市永春县开展. 研究中选取了 10 种不同的湿地植物构建 10 座表面流人工湿地实例工程, 拟从湿地植物的去污能力、生物量、氮磷累积量、景 观美学效应等因素篮选出适宜于亚热带气候条件下在冷季依旧具有较好去除能力的湿地植物, 为亚热带地 区湿地植物的选育以及人工湿地的大规模推广应用奠定基础.

\section{1 材料与方法}

\section{1 研究区概况}

本研究地点位于福建省中部永春县吾峰镇吾西村 $\left(25^{\circ} 13^{\prime} 15^{\prime \prime} \sim 25^{\circ} 33^{\prime} 45^{\prime \prime} \mathrm{N}, 117^{\circ} 41^{\prime} 55^{\prime \prime} \sim 118^{\circ} 31^{\prime} 9^{\prime \prime} \mathrm{E}\right.$ ), 平 均海拔 $800 \mathrm{~m}$, 具有典型的亚热带季风气候, 全年无霜期长达 320 天, 霜冻出现时间为 12 月底至 2 月初, 年 平均气温为 $20.4^{\circ} \mathrm{C}$, 降水量在 $1600 \sim 2100 \mathrm{~mm}$ 之间 ${ }^{[17]}$.

\section{2 人工湿地构建}

共构建 10 座混凝土结构表面流人工湿地实例工程, 每座人工湿地的规模为 $5 \mathrm{~m} \times 2 \mathrm{~m} \times 1 \mathrm{~m}$ (长 $\times$ 宽 $\times$ 深), 采用防水剂做防渗透处理, 以当地红壤土为基质, 深度为 $50 \mathrm{~cm}$, 水位保持在 $30 \mathrm{~cm}$. 选择梭鱼草 (Pontederia cordata)、泽泻 (Alisma plantago-aquatica)、水龙 (Jussiaea repens)、狐尾藻 (Myriophyllum verticillatum)、美人蕉 (Canna indica)、再力花 (Thalia dealbata)、鸭跖草 (Commelina communis)、黄菖蒲 (Iris pseudacorus)、铜钱草 (Hydrocotyle chinensis) 和水芋 (Calla palustris) 共 10 种供试水生/湿生植物. 人工湿地中植物的栽种密度为 4 棵 $/ \mathrm{m}^{2}$.

\section{3 实验运行}

植物栽种时间为 2014 年 6 月, 此时植物处于生长旺盛期, 经过几个月的生长适应期, 人工湿地从 2014 年 6 月一直运行至 2015 年 12 月. 每个实验周期采用间歇运行序批式进水的方式,水力停留时间 (HRT) 为 7 $\mathrm{d}$, 分别于冷季的 2014 年 12 月 1 日 -8 日 (初冬季, 日平均气温 $13.5^{\circ} \mathrm{C}$ )、 2015 年 1 月 5 日-12 日 (深冬季, 
日平均气温 $9.5^{\circ} \mathrm{C}$ ) 、2015 年 11 月 2 日 -9 日 (秋季, 日平均气温 $18.5^{\circ} \mathrm{C}$ ) 及 2015 年 11 月 23 日一 30 日 (深秋 季, 日平均气温 $14.5^{\circ} \mathrm{C}$ ) 各开展 1 次实验, 考察人工湿地在亚热带地区秋、冬季( 冷季) 的运行情况. 通过对比 不同植物配置人工湿地实例工程对典型污染物净化能力, 同时结合生物量和景观美学等因素, 笁选出具有 较强净化能力及环境适应性强的 2 3 种湿地植物.

\section{4 测试指标}

实验期间, 取各人工湿地进水和出水水样, 水样的测试指标主要有 $\mathrm{pH}$ 、铵态氮 $\left(\mathrm{NH}_{4}^{+}-\mathrm{N}\right)$ 、总氮 $(\mathrm{TN})$ 、总 磷 (TP) 以及 COD. $\mathrm{pH}$ 采用玻璃电极法现场测定; $\mathrm{NH}_{4}^{+}-\mathrm{N}$ 浓度采用纳氏试剂分光光度法 ( $\mathrm{HJ} 535-2009$ ) 测 定; TN 浓度采用碱性过硫酸钾消解一紫外分光光度法 (HJ 636-2012) 测定; TP 浓度采用过硫酸钾消解锄酸 铵分光光度法 (GB 11893-1989) 测定; COD 浓度采用重铬酸钾滴定法 (GB/T 11914-1989) 测定. 2015 年 11 月下旬实验结束后, 对人工湿地植物进行收割, 在每个人工湿地中, 分别随机选取 3 个植物样方, 样方面 积为 $1 \mathrm{~m} \times 1 \mathrm{~m}$, 采用收获法收集地上植物样品, 测鲜重. 收集的植物样品带回实验室清洗, 在 $70^{\circ} \mathrm{C}$ 下烘干至 恒重, 计算生物量. 同时将烘干的植物样品研磨, 过 100 目篎放人自封袋保存, 以备分析其氮、磷含量. 植物 样品用 $\mathrm{H}_{2} \mathrm{SO}_{4}-\mathrm{H}_{2} \mathrm{O}_{2}$ 消化后, 采用流动分析仪测全氮含量, 采用钿锑抗比色法 (GB 9837-1988) 测定全磷含 量. 采用 Origin 9.0( Origin Lab, USA) 软件进行数据分析和作图.

\section{2 结果与讨论}

\section{1 人工湿地进水和出水的 $\mathrm{pH}$ 变化}

人工湿地在 4 个实验周期的进水 $\mathrm{pH}$ 值分别为 $6.53 、 6.38 、 7.02$ 和 6.97 , 进水整体接近中性, 且进水 $\mathrm{pH}$ 值的变化受季节变化的影响幅度较小. 生活污水经人工湿地处理后, 出水 $\mathrm{pH}$ 值相对进水 $\mathrm{pH}$ 值变化不明显, 出水 $\mathrm{pH}$ 总体也接近中性 (图 1). 有研究表明, 若出水 $\mathrm{pH}$ 值在中性范围内变化则说明人工湿地运行正常, 没 有出现湿地生物系统崩溃现象 ${ }^{[20]}$.

\section{一 进水 出水}
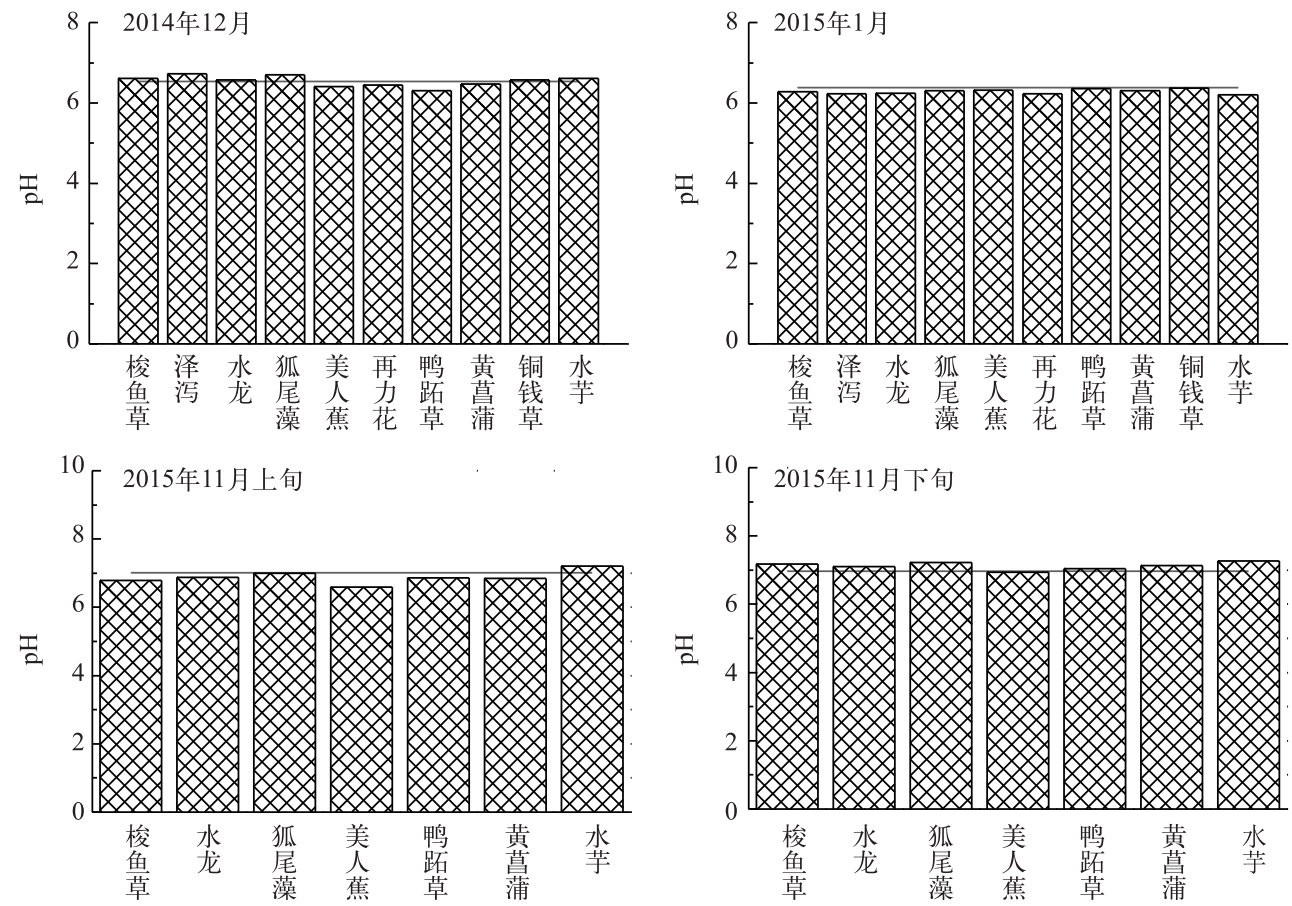

图 1 不同植物配置人工湿地进水和出水 $\mathrm{pH}$ 值的变化

Fig. 1 The influent and effluent $\mathrm{pH}$ in surface flow constructed wetland systems with different vegetation species 


\section{2 人工湿地对 $\mathrm{NH}_{4}^{+} \mathrm{N}$ 的净化效果}

初冬季节人工湿地 (黄菖蒲人工湿地除外)均表现出较好的 $\mathrm{NH}_{4}^{+}-\mathrm{N}$ 处理效果,尤其是水龙 (76.7\%)、狐 尾藻 $(89.3 \%)$ 、美人蕉 $(87.7 \%)$ 、鸭跖草 $(82.3 \%)$ 和铜钱草 $(73.8 \%)$. 黄菖蒲人工湿地的 $\mathrm{NH}_{4}^{+}-\mathrm{N}$ 出水浓度比 进水浓度高, 其可能的原因是, 植物落叶腐败, 从而导致出水 $\mathrm{NH}_{4}^{+}-\mathrm{N}$ 浓度升高. 尹连庆等 ${ }^{[21]}$ 的研究表明温度 能够显著影响植物对 $\mathrm{NH}_{4}^{+}-\mathrm{N}$ 的净化效果, 特别是在冬季, 植物的生命活动降低, 不利于对 $\mathrm{NH}_{4}^{+}-\mathrm{N}$ 的去除. 在 深冬季节, 随着温度的降低, 部分人工湿地对 $\mathrm{NH}_{4}^{+}-\mathrm{N}$ 的去除率出现下降趋势, 但是泽泻 $(74.0 \%$ )、水龙 $(42.2 \%)$ 和美人蕉 $(53.0 \%)$ 人工湿地依旧显示出一定的去除能力, 同时, 此时泽泻、水龙和美人蕉生物量虽 然没有明显的增加, 但是依旧长势较好, 并无枯萎现象, 表明这 3 种植物在冷季依旧具有较好的 $\mathrm{NH}_{4}^{+}-\mathrm{N}$ 去除 能力. 第 2 年秋季人工湿地对 $\mathrm{NH}_{4}^{+}-\mathrm{N}$ 的去除效能出现了较为明显的变化, 所存活的植物中, 人工湿地进水和 出水浓度基本上相差不大, 湿地植物去除 $\mathrm{NH}_{4}^{+}-\mathrm{N}$ 的效果不理想, 只有水龙和水芋依旧显示出较好的 $\mathrm{NH}_{4}^{+}-\mathrm{N}$ 去除效果, 去除率可维持在 $50 \%$ 左右. 造成人工湿地在第 2 年运行过程中 $\mathrm{NH}_{4}^{+}-\mathrm{N}$ 净化效能下降的原因可能 是本实验中人工湿地植物未经收割. 未收割的植物生长已趋于稳定, 所吸收养分已饱和, 从而导致植物的 $\mathrm{NH}_{4}^{+}-\mathrm{N}$ 去除性能下降,进出水 $\mathrm{NH}_{4}^{+}-\mathrm{N}$ 变化不明显 ${ }^{[22]}$. 总的来看, 根据第 1 年的运行效果, 泽泻、水龙和美人 蕉人工湿地实例工程在冷季具有相对较好的 $\mathrm{NH}_{4}^{+}-\mathrm{N}$ 净化效果 (图 2).

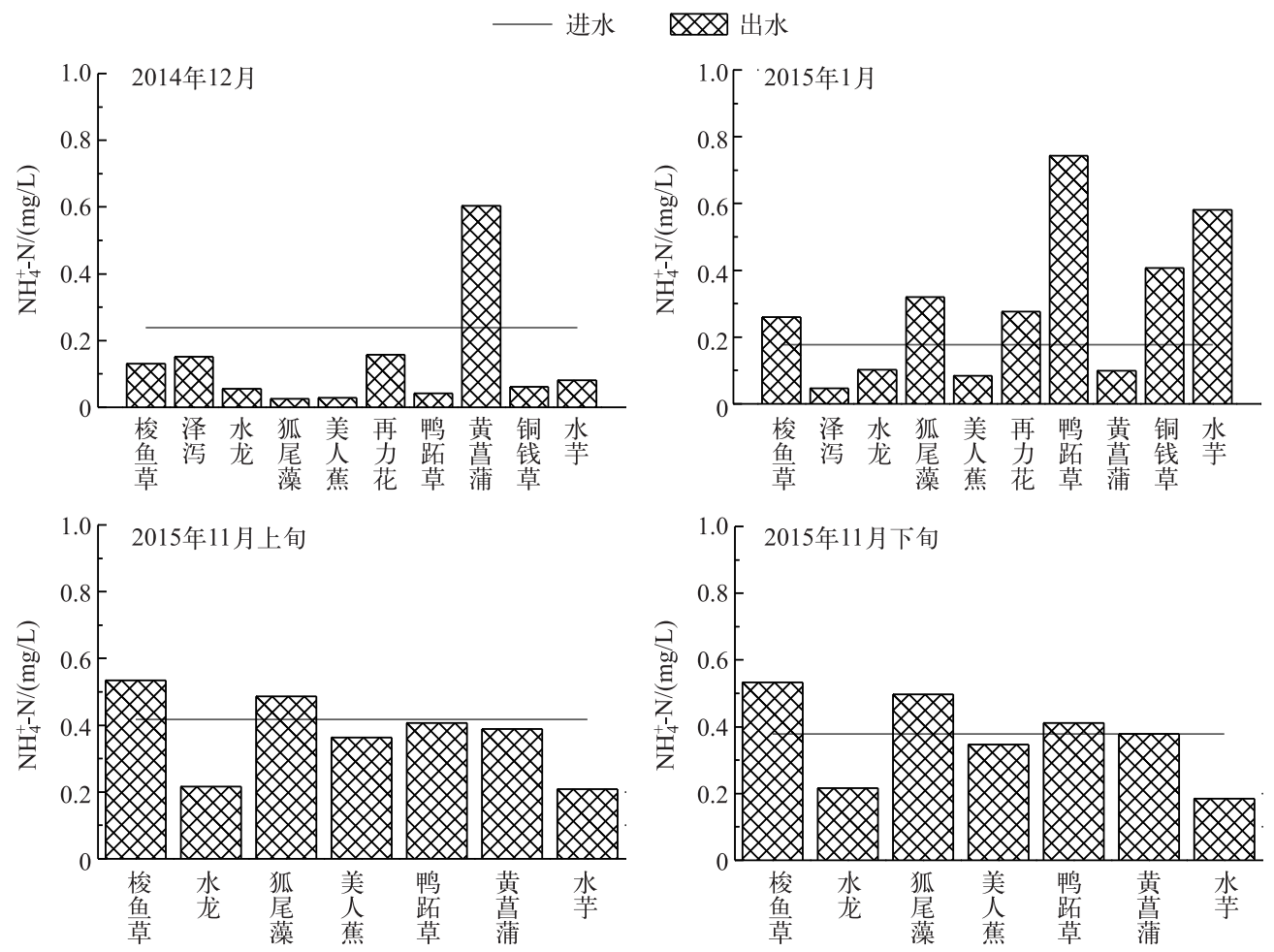

图 2 不同植物配置人工湿地进水和出水 $\mathrm{NH}_{4}^{+}-\mathrm{N}$ 浓度的变化

Fig.2 The influent and effluent concentrations of ammonia nitrogen in surface flow constructed wetland systems with different vegetation species

\section{3 人工湿地对 TN 的净化效果}

初冬季节,栽种不同植物的所有人工湿地实例工程均对 TN 表现出较好的去除效果, 尤其是梭鱼草 $(89.6 \%)$ 、美人蕉 $(90.1 \%)$ 和水芋 $(92.4 \%)$ 人工湿地去除效果最好, 出水 $\mathrm{TN}$ 浓度低于 $0.83 \mathrm{mg} / \mathrm{L}$, 去除率达 到 $90 \%$ 以上. 深冬季节, 各种植物也均表现出较好的 TN 去除效果, 美人蕉湿地对 TN 去除率依旧达到 
$80.3 \%$. 总体而言, 深冬出水 $\mathrm{TN}$ 浓度相对初冬较高, 可能是由于受到气温降低的影响, 湿地内部脱氮微生物 数量及用于酶促含氮有机物水解的相关酶 (如脲酶) 活性下降, 导致脱氮的主要途径受阻, 从而使人工湿地 的 TN 去除能力下降 ${ }^{[23]}$; 此外, 温度的降低导致植物叶片凋落, 在人工湿地内堆积和腐烂, 因此, 低温条件下 植物腐败还会引起含氮物质的释放, 从而使人工湿地中 $\mathrm{TN}$ 浓度也有所升高 ${ }^{[24-25]}$. 第 2 年秋季, 水龙、狐尾 藻、美人蕉、黄菖蒲和水芋人工湿地对 TN 依旧具有较好的处理效果. 综合以上研究结果,栽种有水龙、狐尾 藻、美人蕉和黄菖蒲的人工湿地实例工程在冷季对 TN 也具有较好的去除效果(图 3 ).

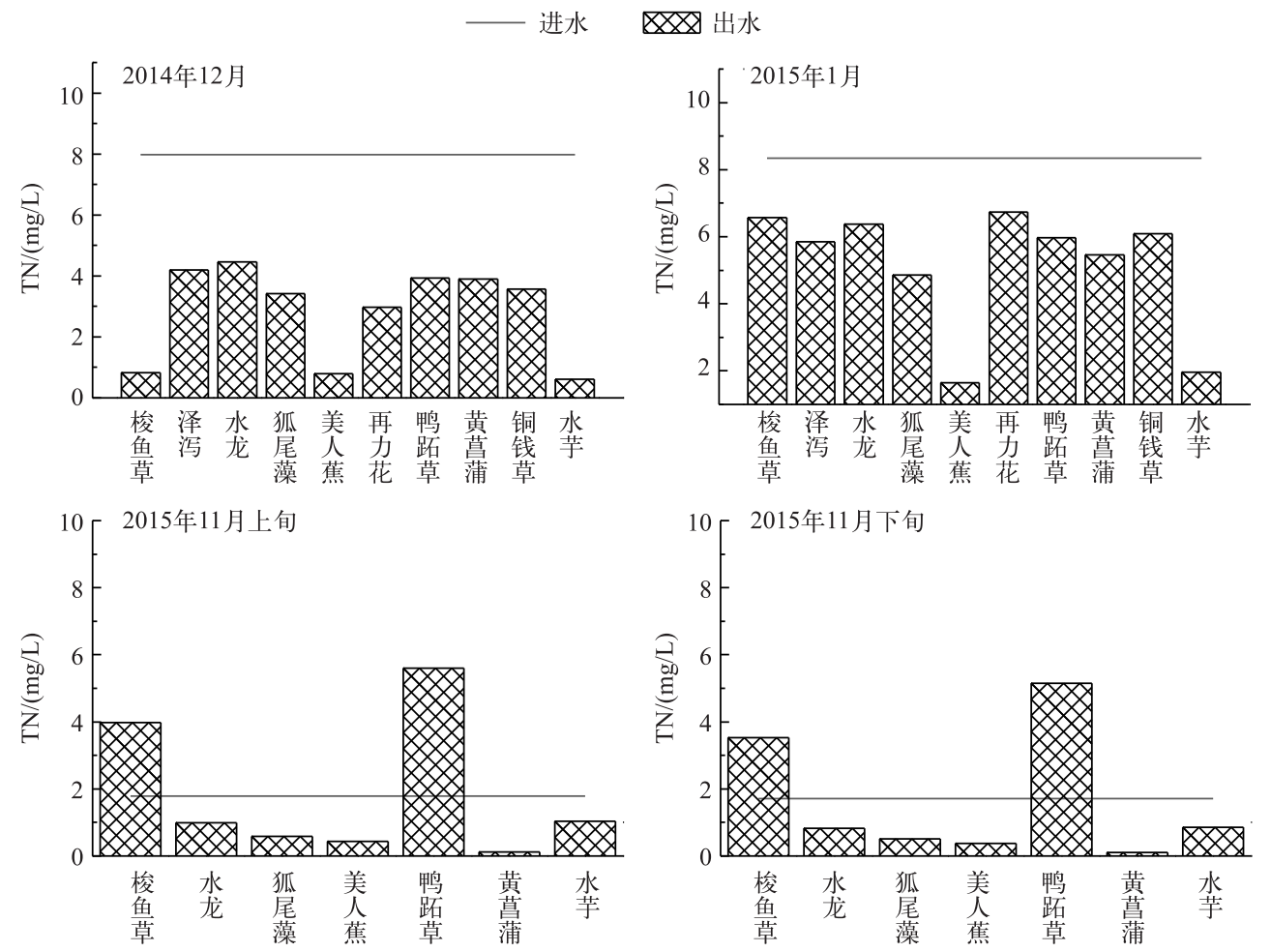

图 3 不同植物配置人工湿地进水和出水 $\mathrm{TN}$ 浓度的变化

Fig. 3 The influent and effluent concentrations of total nitrogen in surface flow constructed wetland systems with different vegetation species

\section{4 人工湿地对 TP 的净化效果}

人工湿地除磷主要依赖湿地基质、水生植物和微生物以及三者之间的联合作用, 通过一系列复杂的物 理、化学以及生物途径实现磷素去除 ${ }^{[26]}$. 运行结果 (图 4) 表明, 初冬季节, 除狐尾藻和鸭跖草人工湿地外, 其 余的人工湿地均对 TP 显示出一定的去除效果, 尤其是再力花人工湿地去除效果最优, 去除率达到 $92.5 \%$, 其次为水芋 $(82.3 \%)$ 、铜钱草 $(76.3 \%)$ 、黄菖蒲 $(70.8 \%)$ 和水龙 $(69.0 \%)$ 人工湿地. 深冬季节人工湿地实例 工程对 TP 的去除效果较差, 只有美人蕉人工湿地实例工程仍然显示出一定的去除能力, 说明温度的下降能 够影响人工湿地除磷能力. 由于植物和微生物的耦合作用是湿地除磷的一个重要机制, 因此温度的下降可 能降低了微生物活性, 从而降低了人工湿地的除磷能力 ${ }^{[26]}$. 此外, 温度的变化可能会引起基质对磷的吸附 和解吸之间发生动态变化, 从而使得磷的去除率出现波动. 第 2 年秋季, 总体而言, 人工湿地实例工程对 TP 的去除效果不明显,其可能的原因是植物未经收割,生长已趋于稳定,所吸收养分已饱和 ${ }^{[22]}$.

\section{5 人工湿地对 COD 的净化效果}

人工湿地对 COD 的去除主要是依靠附着在基质和植物根系中的微生物代谢过程来完成 ${ }^{[27-28]}$. 初冬和 深秋季节的人工湿地实例工程大部分的出水 COD 浓度高于进水浓度, 只有初冬时美人蕉人工湿地实例工程 


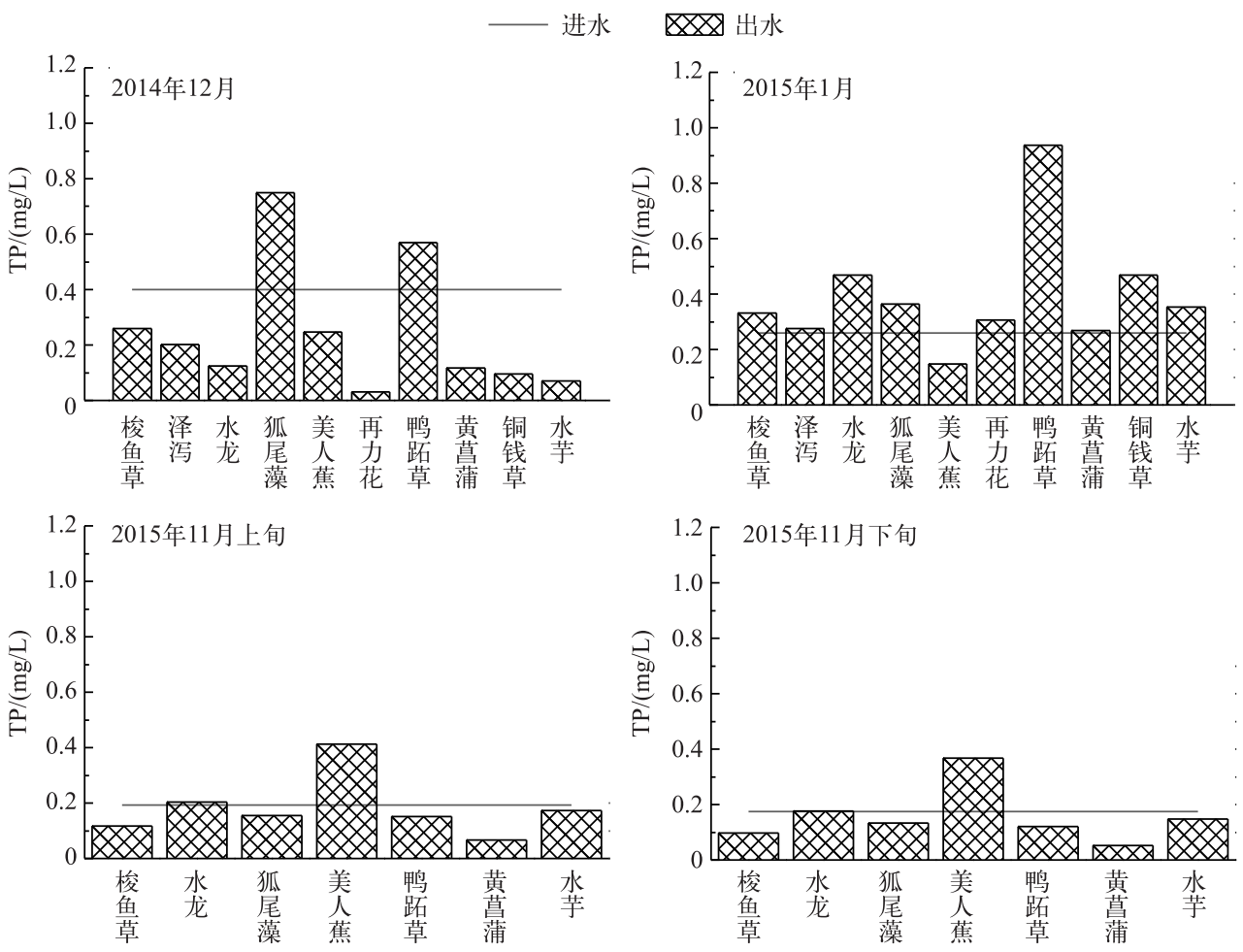

图 4 不同植物配置人工湿地进水和出水 $\mathrm{TP}$ 浓度的变化

Fig.4 The influent and effluent concentrations of total phosphorus in surface flow constructed wetland systems with different vegetation species

显示出一定的 COD 降解能力, 其原因是, 温度的降低导致植物的部分叶片调落, 在人工湿地内堆积和腐烂, 从而引起人工湿地中污水的 COD 浓度增加 ${ }^{[29]} .2015$ 年 1 月和 11 月上旬人工湿地对 COD 具有一定的去除 效果 (图 5). 其主要原因是永春县秋季温度相对较高, 植物没有调零和腐败, 没有增加人工湿地内的 COD 浓 度, 此外, 人工湿地内的微生物还能在一定程度上去除 $\mathrm{COD}^{[30]}$.

\section{6 植物生物量和氮、磷累积量}

植物对污染物的吸收是人工湿地净化污染物的重要途径之一, 考察人工湿地植物的生物量和植物对 氮、磷的累积量等指标也是篮选适宜人工湿地植物的重要参考依据 ${ }^{[31]}$. 根据实验观测结果, 人工湿地在运 行第 2 年, 由于虫害、自然枯萎等原因, 泽泻、再力花和铜钱草 3 种植物在运行过程中出现了自然死亡现象, 达到了天然的植物篮选结果, 说明这 3 种植物不适合用于当地的人工湿地构建. 实验过程中发现, 水芋人工 湿地运行前后, 长势相对不好, 株高、株数和生物量没有明显的增长, 单位面积水芋吸收氮磷贡献率较小, 因 此, 没有测定水芋的生物量以及水芋体内氮、磷含量. 6 种人工湿地植物的鲜重均大于 $1.32 \mathrm{~kg} / \mathrm{m}^{2}$, 均具有较 大的生物量, 其中水龙 $\left(0.46 \mathrm{~kg} / \mathrm{m}^{2}\right)$ 、美人蕉 $\left(0.30 \mathrm{~kg} / \mathrm{m}^{2}\right)$ 和黄菖蒲 $\left(0.32 \mathrm{~kg} / \mathrm{m}^{2}\right)$ 具有更高的干重含量, 说明 水龙、美人蕉和黄菖蒲人工湿地实例工程具有更大的干生物量. 水龙、美人蕉和黄菖蒲相对于其他植物体内 的氮、磷含量较高, 其体内氮含量分别达到 $6.43 、 4.60$ 和 $4.77 \mathrm{~g} / \mathrm{m}^{2}$, 而磷含量分别达到 $0.50 、 1.01$ 和 0.71 $\mathrm{g} / \mathrm{m}^{2}$ (图 6), 说明水龙、美人蕉和黄菖蒲在单位面积人工湿地中能够更好地积累氮、磷元素, 从而有利于人 工湿地实例工程对氮、磷元素的去除. 


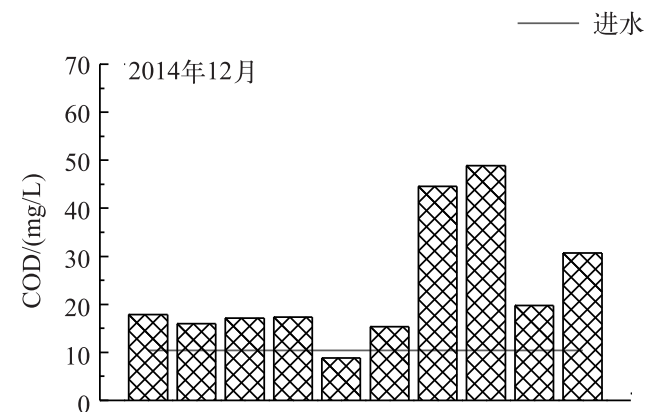

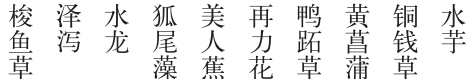

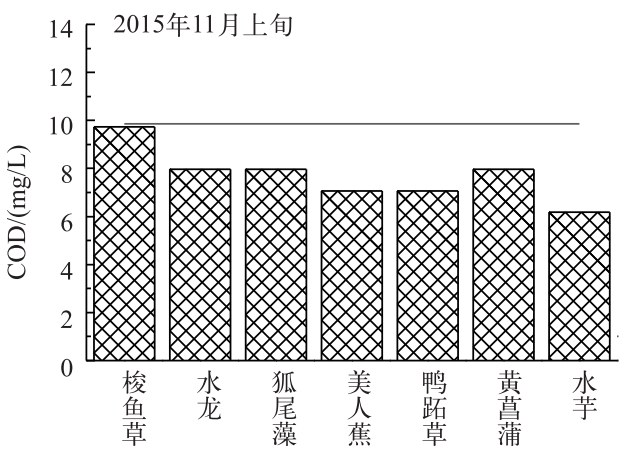

$x \times$ 出水
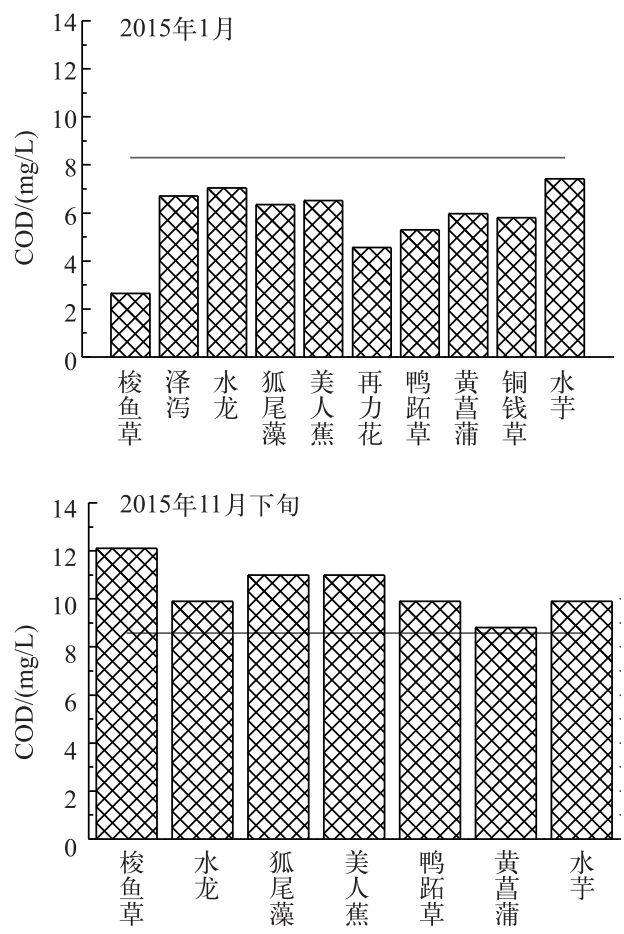

图 5 不同植物配置人工湿地进水和出水 $\mathrm{COD}$ 浓度的变化

Fig.5 The influent and effluent concentrations of COD in surface flow constructed wetland systems with different vegetation species
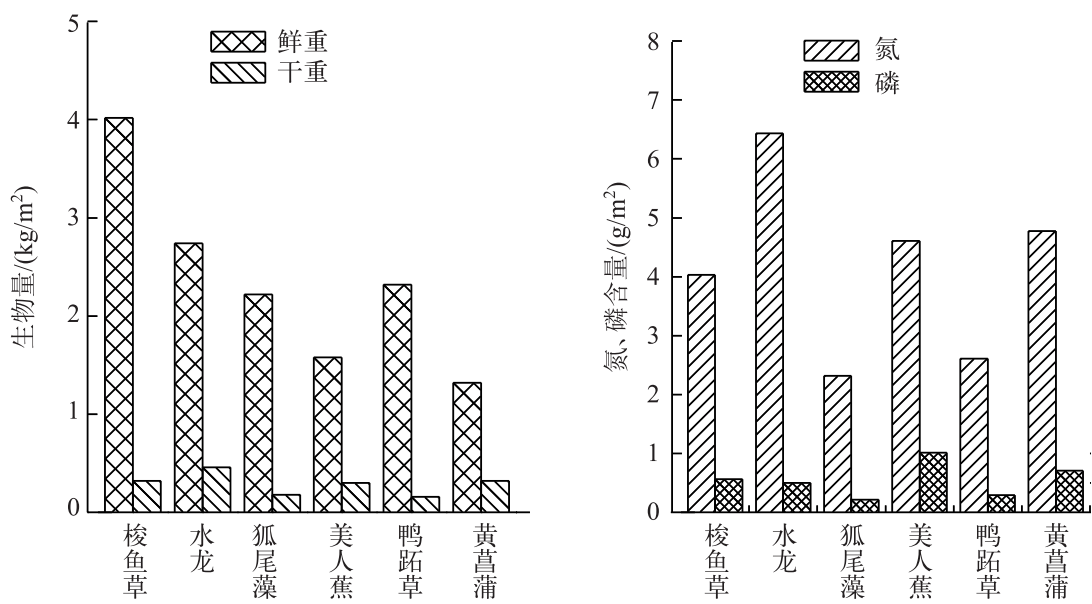

图 6 单位面积人工湿地中植物鲜重和干重及植物体内氮、磷含量

Fig. 6 The fresh and dry weight of vegetations and nutrients ( $\mathrm{N}$ and $\mathrm{P}$ ) content uptake by the above ground biomass per unit area of surface flow constructed wetland systems 


\section{3 结论}

本研究结果表明,第 1 年水龙和美人蕉人工湿地具有较好的 $\mathrm{NH}_{4}^{+}-\mathrm{N}$ 净化效果; 同时,水龙和美人蕉有利 于人工湿地 TN 的去除; 初冬季节, 水龙和美人蕉又具有较好的总磷去除性能; 另外, 水龙和美人蕉在单位面 积人工湿地中还能够更好地积累氮、磷元素, 从而有利于人工湿地对氮、磷元素的去除. 综上所述, 本实验中 的水龙和美人蕉人工湿地实例工程在冷季具有较好的氮、磷去除能力, 同时又具有较大的生物量以及较高 的氮、磷积累能力, 可选为相对适宜的人工湿地植物, 适合运用于亚热带地区处理生活污水的人工湿地实例 工程构建.

\section{4 参考文献}

[ 1 ] Peng XY, Zhang P, Jia CX et al. Discharge characteristic of the rural domestic wastewater and its influencing factors in the three gorges reservoir region of chongqin. Journal of Agro-Environment Science, 2009, 29(4) : 758-763. [彭绪亚, 张鹏, 贾传兴等. 重庆三峡库区农村生活污水排放特征及影响因素分析. 农业环境科学学报, 2009, 29(4): 758-763.

[ 2 ] Gangte ML. Research of the purification effect and law of compound ecological treatment technology for distributed domestic sewage in Hainan area[Dissertation]. Qiqihar: Qiqihar University, 2012. [ 钢特木勒. 复合型生态处理技术对海南分 散式生活污水净化效果及规律研究 [学位论文]. 齐齐哈尔: 齐齐哈尔大学, 2012].

[ 3 ] Chen L. Purification of rural domestic sewage with high COD and $\mathrm{NH}_{4}^{+}-\mathrm{N}$ through aerobic/anaerobic aeries artficial wetland [Dissertation]. Qingdao: Ocean University of China, 2013. [陈蕾. 好氧/厌氧串联人工湿地对农村生活污水高 COD 和 $\mathrm{NH}_{4}^{+}-\mathrm{N}$ 的净化研究 [学位论文]. 青岛: 中国海洋大学, 2013.]

[ 4 ] Cao J. Performance of constructed wetland for rural sewage treatment[Dissertation]. Hangzhou: Zhejiang University, 2007. [曹杰. 人工湿地对农村生活污水的处理效果研究 [学位论文]. 杭州: 浙江大学, 2007.]

[ 5 ] Qian HY, Chen K, Dai XZ et al. Present status and technology on decentralized treatment of domestic sewage in rural areas. Chinese Agricultural Science Bulletin, 2014, 30(33): 176-180. [ 钱海燕, 陈葵, 戴星照等. 农村生活污水分散式 处理研究现状及技术探讨. 中国农学通报, 2014, 30(33): 176-180.]

[ 6 ] Biggs BJF, Goring DG, Nikora VI. Subsidy and stress responses of stream periphyton to gradients in water velocity as a function of community growth form. Journal of phycology, 1998, 34: 598-607.

[ 7 ] Huang J, Reneau RB, Hagedorn C. Nitrogen removal in constructed wetlands employed to treat domestic wastewater. Water Research, 2000, 34: 2582-2588.

[ 8 ] Liang K, Wang QS, Wang FH et al. Research progresses in domestic wastewater treatment by constructed wetlands. Journal of Agro-Environment Science, 2014, 33(33): 422-428. [梁康, 王启炼, 王飞华等. 人工湿地处理生活污水的研 究进展. 农业环境科学学报, 2014, 33(3): 422-428.]

[ 9 ] Chen JJ, Zheng C, Zheng SK. Pollutant purification performance of a surface flow constructed wetland planted with different aquatic macrophytes and their combination. Acta Scientiae Circumstantiae, 2008, 28(10): 2029-2035. [陈进军, 郑 抽, 郑少奎. 表面流人工湿地中水生植被的净化效应与组合系统净化效果. 环境科学学报, 2008, 28(10): 2029-2035.]

[10] Cheng SP, Wu ZB, Kuang QJ. Macrophytes in Artificial Wetland. J Lake Sci, 2002, 14(2) : 179-184. DOI: 10.18307/ 2002.0213. [成水平, 吴振斌, 况其军. 人工湿地植物研究. 湖泊科学, 2002, 14(2): 179-184.]

[11] Xu JT. The tolerance and mechanism of typical wetland plants to ammonia and organic pollutant [Dissertation]. Qingdao: Shandong University, 2012. [徐景涛. 典型湿地植物对氨氮、有机污染物的耐受性及其机理研究 [ 学位论文]. 青岛: 山东大学, 2012.]

[12] Liao XD, Luo SM. Treatment effect of constructed wetlands on organic matter in wastewater from pig farm. The Journal of Applied Ecology, 2002, 13(1): 113-117. [廖新俤, 骆世明. 人工湿地对猪场废水有机物处理效果的研究. 应用生 态学报, 2002, 13(1): 113-117.]

[13] Ma AN. Study on screening of dominant wetland plant species and purification by constructed wetland in Beijing[Dissertation]. Beijing: Capital Normal University, 2007. [马安娜. 北京地区人工湿地优势植物篮选及净化效果研究 [ 学位 论文]. 北京: 首都师范大学, 2007.]

[14] Vymazal J, Kröpfelová L, Removal of organics in constructed wetlands with horizontal sub-surface flow: A review of the field experience. Science of the Total Environment, 2008, 407: 3911-3922. 
[15] Maine MA, Suñe N, Hadad N et al. Temporal and spatial variation of phosphate distribution in the sediment of a free water surface constructed wetland. Science of the Total Environment, 2007, 380: 75-83.

[16] Wu XL. Sereening of plants in constructed wetland for waste water treatment and the purification effects on the livestoek and poultry wastewater[Dissertation]. Chengdu: Sichuan Agricultural University, 2010. [吴晓莉. 人工湿地植物䇥选及其 对畜禽养殖废水的净化研究 [学位论文]. 成都: 四川农业大学, 2010.]

[17] Xiang XM, Song C, Zhou JT et al. Constructed wetlands for wastewater treatment: progress, problem and improving measures. Enuivonmental Science and Technology, 2006, 29(10): 101-102. [项学敏, 宋晨, 周集体等. 人工湿地水处理技 术研究进展存在问题与改进. 环境科学与技术, 2006, 29(10): 101-102.]

[18] Chen YH, Wu XF, Jiang LJ et al. Screening and evaluation of plant purification potential for phytoremediation of sanitary sewage. Acta Scientiae Circumstantiae, 2008, 28(8): 1549-1554. [ 陈永华, 吴晓芙, 蒋丽鹃等. 处理生活污水湿地植 物的篮选与净化潜力评价. 环境科学学报, 2008, 28(8): 1549-1554.]

[19] Chen YH, Wu XF, Hao J et al. Selection and purification potential evaluation of woody plant in vertical flow constructed wetlands in the subtropical are. Environmental Science, 2014, 35(2): 585-591. [陈永华, 吴晓芙, 郝君等. 亚热带地 区潜流人工湿地木本植物篮选与净化潜力评价. 环境科学, 2014, 35(2): 585-591.]

[20] Zhang HH, Huang YM. Variation in $\mathrm{pH}$, acidity and alkalinity in long-term operation of the subsurface flow constructed wetland as a domestic wastewater treatment system. Journal of Southwest University: Natural Science Edition, 2012,34 (5) : 63-67. [张欢欢, 黄玉明. 潜流人工湿地污水处理系统长期运行中 $\mathrm{pH}$ 及酸度和碱度的变化. 西南大学学报: 自然科学版, 2012, 34(5): 63-67.]

[21] Yin LQ, Gu RH. Ammonia nitrogen removal mechanism and affecting factors of constructed wetland. Enviromental Engineering, 2008, 6(SI) : 151-155. [尹连庆, 谷瑞华. 人工湿地去除氨氮机理及影响因素研究. 环境工程, 2008,6 (SI) : 151-155.]

[22] Yu HB, Yang ZJ, Xiao RL et al. Absorption capacity of nitrogen and phosphorus of aquatic plants and harvest management research. Acta Prataculturae Sinica, 2013, 22 (1): 294-299. [余红兵, 杨知建, 肖润林等. 水生植物的氮磷吸收能 力及收割管理研究. 草业学报, 2013, 22(1): 294-299.]

[23] Huang J, Wang SH, Yan L et al. Distribution characteristic of urease activity in subsurface constructed wetlands. Journal of Southeast University: Natural Science Edition, 2008, 38 (1) : 166-169. [黄娟, 王世和, 滒璐等. 潜流型人工湿地的 脲酶活性分布特性. 东南大学学报: 自然科学版, 2008, 38(1): 166-169.]

[24] Zhang Z, Fu RB, Gu GW et al. Analyse of nitrogen removal pathways and their effect factors in constructed wetland. Ecology and Environment, 2006, 15(6): 1385-1390. [张政, 付融冰, 顾国维等. 人工湿地脱氮途径及其影响因素分析. 生态环境学报, 2006, 15(6): 1385-1390.]

[25] Zhou LF, Zou F, Li YZ. Continous influence of submerged plant decomposition on water quality in constructed wetland. Journal of Soil and Water Conservation, 2013, 27(6): 119-123. [周林飞, 邹飞, 李颖卓. 沉水植物腐解对人工湿地 水质的持续影响研究. 水土保持学报, 2013, 27(6): 119-123.]

[26] Li XD, Sun TH, Li HB et al. Current researches and prospects of phosphorus removal in constructed wetland. Acta Ecologica Sinica, 2007, 27 (3) : 1226-1232. [李晓东, 孙铁珩, 李海波等. 人工湿地除磷研究进展. 生态学报, 2007, 27 (3) : 1226-1232.]

[27] Xu D, Xu J, Wu J et al. Studies on the phosphorus sorption capacity of substrates used in constructed wetland systems. Chemosphere, 2006, 63: 344-352.

[28] Xu DX, Hai RT, Ding WM et al. Comparison of purification efficiency of septic tank effluent by artificial wetland. Environmental Science and Technology, 2009, 32(8): 164-168. [徐德星, 海热提, 丁文明等. 人工湿地对化粪池出水净化 效果的对比研究. 环境科学与技术, 2009, 32(8): 164-168.]

[29] Zhang J, Shao WS, He M et al. Treatment performance and enhancement of subsurface constructed wetland treating polluted river water in winter. Environmental Science, 2006, 27(8):1560-1564. [张建, 郡文生, 何苗等. 潜流人工湿地处 理污染河水冬季运行及升温强化处理研究. 环境科学, 2006, 27(8): 1560-1564.]

[30] Akratos CS, Tsihrintzis VA. Effect of temperature, HRT, vegetation and porous media on removal efficiency of pilot-scale horizontal subsurface flow constructed wetlands. Ecological Engineering, 2007, 29: 173-191.

[31] Zhang W, Zhao J, Lang XM et al. Progress in studies on pollutant removal by microorganisms in constructed wetlands. Chinese Journal of Environmental Engineerin, 2010, 4(4): 721-728. [张巍, 赵军, 郎咸明等. 人工湿地系统微生物去除 污染物的研究进展. 环境工程学报, 2010, 4(4) 721-728.] 